\title{
Dissipation Dynamics of flubendiamideon Capsicum in Open Field and Poly House Conditions
}

\author{
VL Pathipati ${ }^{1}$, Singh T.V.K ${ }^{2}$, Vemuri S.B ${ }^{3}$, Reddy, R.V.S.K ${ }^{4}$, Bharathi N.B ${ }^{5}$ \\ ${ }^{1}$ Assistant Professor (Entomology) and Vice Principal, HPT, Dr YSR Horticultural University, \\ Andhra Pradesh \\ ${ }^{2}$ Emeritus Scientist (ICAR), PJTSAU, Rajendranagar, Hyderabad, Telangana. \\ ${ }^{3}$ Principal Scientist (Ento) \& Head, AINP on Pesticide Residues, PJTSAU, Rajendranagar, \\ Hyderabad, Telangana. \\ ${ }^{4}$ Director of Extension, Dr YSR Horticultural University, Andhra Pradesh \\ ${ }^{5}$ Associate Professor, Department of Plant Pathology,PJTSAU, Rajendranagar, Hyderabad, \\ Telangana.
}

\begin{abstract}
Studies were undertaken to establish dissipation dynamics of commonly used insecticide at recommended dose both in open field and poly house situations to assess the differences in rate of dissipation, and also to recommend Pre-Harvest Intervals based on MRLs established by CAC and FSSAI. Utilizing flubendiamide 20\%WG@48 g a.i. ha-1sprayed at three times and capsicum samples collected at regular intervals were analysed for residues.. The dissipation pattern of insecticides varied in poly houses and open fields, where initial deposits were comparatively higher and dissipated slowly in poly houses, Spray of flubendiamide at recommended dose resulted in $2.40 \mathrm{mg} \mathrm{kg}-1$ initial deposit at 2 hours after spray which dissipated to BDL by 10th day in poly house. However, as the Codex MRL is $2 \mathrm{mg} \mathrm{kg-1,} \mathrm{a} \mathrm{PHI} \mathrm{of} 1$ day is ideal for food safety. Whereas in open field, $2.13 \mathrm{mg} \mathrm{kg}$-linitial deposit at 2 hours after spray which dissipated to BDL by 10th day in open field.
\end{abstract}

Keywords: Capsicum, polyhouse, openfield, dissipation, flubemdiamide, QuEChERS,LC MS/MS

\section{INTRODUCTION}

Capsicum (Capsicum annuum L. var. grossumSendt.) is also called as bell pepper or sweet pepper and is one of the most popular and highly remunerative annual herbaceous vegetable crop in India and suffers major quantitative and qualitative loss in production due to capsicum thrips, ScirtothripsdorsalisHood and yellow mite, Polyphagotarsonemuslatus (Banks) and fruit borers Helicoverpaarmigera(Hubner). A number of pesticides are being frequently used, to combat these pests. However, some of these insecticides leave residues on fruits and these residues may persist up to harvest. Presence of pesticide residues in the harvested capsicum is posing problem at the time of export and in recent times importing countries have rejected few consignments. Pesticide use has increased rapidly over the last two decades at the rate of $12 \%$ per year (Thacker et al., 2005[1]). Many farm gate capsicum samples showed presence of insecticide residues (Singh et al., 1999) [2].As per insecticides Act of 1968 (www.cibrc.nic.in)[3], 37 insecticide formulations are registered and recommended for use on capsicum targeting various pests. In recent years due to the support of the Government under National Horticulture Mission (NHM), capsicum is widely cultivated under poly house conditions. Since the persistence and dissipation of insecticides in poly houses will be different from normal conditions, the present study is proposed to monitor the pesticide usage on capsicum, dissipation studies of recommended pesticides both in poly house and open field conditions, so as to recommend the safe waiting periods based on the Maximum Residue Limits (MRLs) calculated, as it helps in recommending risk mitigation protocols for food safety.

\section{MATerials AND MethodS}

\subsection{Preparation of Working Standards}

Certified Reference Materials (CRMs) of flubendiamide obtained from Dr. Erhenstorfer, Germany were used to prepare primary standards. Intermediary and working standards were prepared using 


\section{VL Pathipati et al.}

acetone and hexane as solvents ( $1: 9$ ratio). Working standards of all the pesticides were prepared in the range of $0.01 \mathrm{ppm}$ to $0.5 \mathrm{ppm}$ in $10 \mathrm{ml}$ calibrated graduated volumetric flask using distilled $\mathrm{n}$ hexane as solvent. All the standards were stored in deep freezer maintained at $-40^{\circ} \mathrm{C}$.

\subsection{Limit of Detection and Linearity of Insecticide}

The working standards of flubendiamidewere injected in Liquid Chromatograph with Photo Diode Array (PDA). The detector for estimating the lowest quantity of insecticides which can be detected under standard operating parameters are given in Table 1.

Table1. Details of LC-MS/MS operating parameters for the analysis of flubendiamide

\begin{tabular}{|c|c|c|c|c|}
\hline LC-MS/MS & \multicolumn{4}{|c|}{ SHIMADZU LC-MS/MS 8040} \\
\hline Detector & \multicolumn{4}{|c|}{ Mass Spectrophotometer } \\
\hline Column & \multicolumn{4}{|c|}{ KINETEX, 100 X 3, 2 um } \\
\hline Column Oven Temperature & \multicolumn{4}{|l|}{$40^{\circ} \mathrm{C}$} \\
\hline Retention Time (RT) & \multicolumn{4}{|l|}{5.10} \\
\hline Nebulizing gas & \multicolumn{4}{|l|}{ Nitrogen } \\
\hline Nebulizing flow gas & \multicolumn{4}{|l|}{2.0 lit. $\mathrm{min}^{-1}$} \\
\hline Pump Mode/ flow & \multicolumn{4}{|c|}{ Gradient/ $0.4 \mathrm{ml} . \mathrm{min}^{-1}$} \\
\hline Retention time & \multicolumn{4}{|l|}{5.10} \\
\hline \multirow[t]{4}{*}{ LC Program } & \multicolumn{4}{|c|}{ A : Ammonium formate in water } \\
\hline & \multicolumn{4}{|c|}{ B : Ammonium formate in methanol } \\
\hline & Insecticide & Time & methanol & Water \\
\hline & Flubendiamide & 8.01 & 60 & 40 \\
\hline \multirow[t]{2}{*}{ Precursor ion and Quantifier ion } & Insecticide & Precursor ion & \multicolumn{2}{|c|}{ Quantifier ion } \\
\hline & Flubendiamide & 681.10 & \multicolumn{2}{|c|}{254.05} \\
\hline
\end{tabular}

Under LC operational parameters given in Table 1, the retention time of flubendiamideis5.10 min, respectively. Working standards of above insecticide $(0.05 \mathrm{ppm}, 0.075 \mathrm{ppm}, 0.10 \mathrm{ppm}, 0.25 \mathrm{ppm}$ and $0.50 \mathrm{ppm}$ ) was injected six times and the linearity lines were drawn.

For confirmatory analysis, samples were also injected in LC-MS/MS. The LC operating parameters for flubendiamide detection and estimation are presented in Table 1.

Based on the response of the detector (PDA) to different quantities (ng) of CRM standards injected under the LC- MS/MS operational parameters given in table 1, it was found that the LOD (limit of detection) for flubendiamidewas $0.05 \mathrm{ng}$ and the linearity was in the range of $0.05 \mathrm{ng}$ to $0.10 \mathrm{ng}$, respectively, as given in Fig 1.

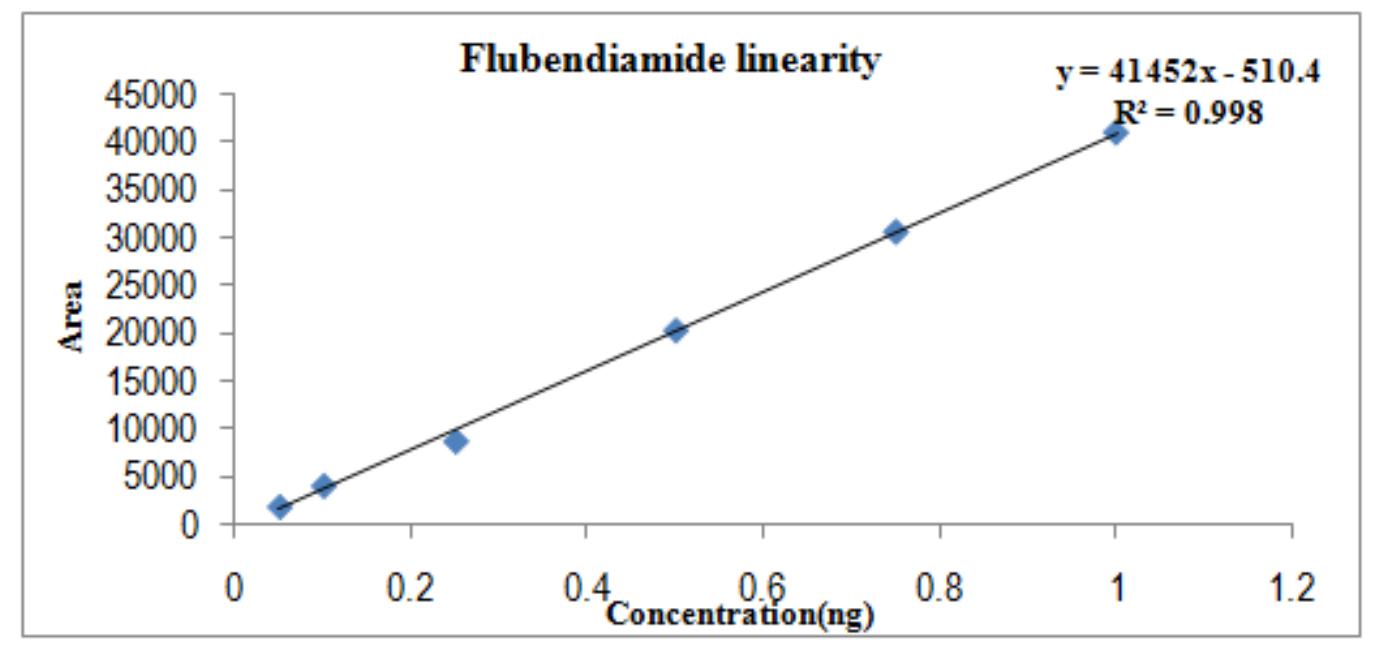

\subsection{Method Valilidation and Fortification Recoveries}

Prior to pesticide application and field sample analysis, the residue analysis method was validated following the SANCO document (12495/2011). The capsicum fruits $(5 \mathrm{~kg})$ collected from untreated control plots were brought to the laboratory, homogenized using Robot Coupe Blixer (High volume homogenizer) and $15 \mathrm{~g}$ sample was taken in to $50 \mathrm{ml}$ centrifuge tubes. The required quantity of Flubendiamideintermediary standard prepared from CRMs were added to each sample to get fortification levels of $0.05 \mathrm{ppm}, 0.25 \mathrm{ppm}$ and $0.5 \mathrm{ppm}$, in three replications each. These foritifcation 
levels are selected to know the suitability of the method to detect and quantify pesticides in capsicum below Maximum Residue Limits (MRLs) of Codex Alimentarius Commission (CAC). The AOAC official method 2007.01 (Pesticide Residues of Foods by Acetonitrile Extraction and Partitioning with Magnesium Sulfate) was slightly modified to suit to the facilities available at the laboratory and the same was validated for estimation of LOQ (Limit of Quantification) of above mentioned pesticides in Capsicum matrix. The QuEChERSmethod was followed, the final extract of the sample for LC analysis, filtered $1 \mathrm{ml}$ final extract (equal to $0.5 \mathrm{~g}$ sample) was directly injected in LC and the residues of pesticides recovered from fortified samples were calculated using the following formula.

Sample weight $(15 \mathrm{~g}) \mathrm{X}$ aliquot taken

Wt of the Sample analysed =

Volume of acetonitrile (30 ml)

\section{RESULTS AND DISCUSSION}

The dissipation dynamics of flubendiamide was studied in open field and poly house situations by collecting samples at $0,1,3,5,7,10,15$ and 20 days after third spray. In open field situation, initial deposits of $2.13 \mathrm{mg} \mathrm{kg}$ offlubendiamide detected at 2 hours after last spray, dissipated to 1.27, $0.97,0.33$ and $0.12 \mathrm{mg} \mathrm{kg}-1$ and Below Determination Level (BDL) of $0.05 \mathrm{mg} \mathrm{kg}-1$ by 1, 3, 5,7 and 10 days after last spray, respectively and dissipated by 15.33, 35.33, 78.00, 92.00 and $100 \%$ at 1, 3, 5, 7 and 10 days, respectively. The regression equation was $\mathrm{Y}=3.23+(-0.126)$ Xwith $\mathrm{R} 2$ of 0.894.Maximum Residue Limits (MRLs) are not fixed for flubendiamide on capsicum as per FSSAI, while Codex Alimentarius Commission (CAC)has set as $2 \mathrm{mg} \mathrm{kg}-1$. Based on the present study, safe waiting period of 10 days can be suggested as the initial deposits are less than the MRL. The half-life of flubendiamide on capsicum was 1.91 days.

Initial deposits of $2.40 \mathrm{mg} \mathrm{kg}-1$ flubendiamide were detected at 2 hours after last spray, which dissipated to Below Determination Level (BDL) of $0.05 \mathrm{mg} \mathrm{kg}-1$ by $15^{\text {th }}$ day in poly house conditions. The initial deposits dissipated to $1.73,1.34,0.84,0.33$ and $0.13 \mathrm{mg} \mathrm{kg}-1$ and Below Determination Level (BDL) of $0.05 \mathrm{mg} \mathrm{kg}-1$ in 1, 3,5, 7, 10 and 15 days after last spray, respectively. The residues dissipated by 27.91, 61.27, 65.00, 86.25 and $94.58 \%$ at $1,3,5,7$ and 10 days, respectively. The regression equation was $\mathrm{Y}=3.461+(-0.100) \mathrm{X}$ with $\mathrm{R} 2$ of 0.944 .Maximum Residue Limits (MRLs) are not fixed for flubendiamide on capsicum as per FSSAI, while Codex Alimentarius Commission (CAC) set as $2 \mathrm{mg} \mathrm{kg-1.}$

Based on the present study, safe waiting period of 20 day can be suggested as the initial deposits are less than the MRL. The half-life of flubendiamide on capsicum was 3.15 days.It is evident that there is a clear difference in dissipation pattern of flubendiamide in poly house and open fields. Initial deposit of $2.40 \mathrm{mg} \mathrm{kg}-1$ was recorded in poly house, where as in open fields it was $2.13 \mathrm{mg} \mathrm{kg}-1$, reaching Below Determination Level (BDL) of $0.05 \mathrm{mg} \mathrm{kg}-1$ by 15 th day and 10th day, respectively, As per CIBRC and Insecticide Act, 1968, flubendiamide is recommended for use on capsicum @ $48 \mathrm{~g}$ a.i. ha-1 for controlling fruit borer. The same dosage was used in the present study to know the dissipation dynamics in two situations and it is evident that $0.76 \mathrm{mg} \mathrm{kg}-1$ initial deposits dissipated to BDL level by 7th day in open field situation, and the findings of present investigation are in agreement with the results of

Table2. Dissipation of flubendiamide in capsicum in open fieldsconditions

\begin{tabular}{|c|c|c|c|c|c|}
\hline \multirow{2}{*}{ Days after last spray } & \multicolumn{4}{|c|}{ Residues of flubendiamide $\left(\mathrm{mg} \mathrm{kg}^{-1}\right)$} & \multirow{2}{*}{ Dissipation \% } \\
\hline & R1 & $\mathbf{R 2}$ & $\mathbf{R 3}$ & Average & \\
\hline 0 & 1.61 & 1.46 & 1.44 & 1.50 & 0.00 \\
\hline 1 & 1.37 & 1.20 & 1.22 & 1.27 & 15.33 \\
\hline 3 & 0.85 & 1.05 & 1.01 & 0.97 & 35.33 \\
\hline 5 & 0.33 & 0.34 & 0.33 & 0.33 & 78.00 \\
\hline 7 & 0.12 & 0.11 & 0.12 & 0.12 & 92.00 \\
\hline 10 & BDL & BDL & BDL & $\mathrm{BDL}$ & 100.00 \\
\hline 15 & BDL & BDL & BDL & BDL & -- \\
\hline 20 & BDL & BDL & BDL & BDL & -- \\
\hline Regression equation & \multicolumn{5}{|c|}{$\mathrm{Y}=3.23+(-0.126) \mathrm{X}$} \\
\hline $\mathrm{R}^{2}$ & \multicolumn{5}{|c|}{0.894} \\
\hline Half-life & \multicolumn{5}{|c|}{1.91 days } \\
\hline
\end{tabular}




\section{VL Pathipati et al.}

Sahooet al. (2009)[4] who reported that flubendiamide sprayed on capsicum @ $60 \mathrm{~g}$ a.i. ha-1 resulted in initial deposit of $1.06 \mathrm{mg} \mathrm{kg}-1$ and dissipated to BDL in 7 days and at higher dose, it took 10 days. Sharma and Parihar (2013)[5] who reported that flubendiamide persisted up to 5 days after application on tomato @ $48 \mathrm{~g}$ a.i. ha1. Similar results were reported by Kooneret al. (2010) [6] who reported that flubendiamide persisted up to 5 days after application on tomato @ $48 \mathrm{~g}$ a.i. ha-1.The flubendiamide in poly house (controlled environment) dissipated at very slow rate and degraded to BDL by 15 th day. Similar trends were also reported by many workers on other vegetables as well.

Table3. Dissipation of flubendiamide in capsicum in poly house conditions

\begin{tabular}{|c|c|c|c|c|r|}
\hline \multirow{2}{*}{ Days after last spray } & \multicolumn{4}{|c|}{ Residues of flubendiamide $\left.\mathbf{( m g ~ k g}^{-1}\right)$} & \multirow{2}{*}{ Dissipation \% } \\
\cline { 2 - 5 } & $\mathbf{R 1}$ & $\mathbf{R 2}$ & $\mathbf{R 3}$ & Average & \\
\hline 0 & 2.59 & 2.24 & 2.36 & 2.40 & 0.00 \\
\hline 1 & 1.61 & 1.71 & 1.88 & 1.73 & 27.91 \\
\hline 3 & 1.36 & 1.33 & 1.31 & 1.34 & 61.27 \\
\hline 5 & 0.85 & 0.78 & 0.88 & 0.84 & 65.00 \\
\hline 7 & 0.33 & 0.33 & 0.33 & 0.33 & 86.25 \\
\hline 10 & 0.13 & 0.12 & 0.13 & 0.13 & 94.58 \\
\hline 15 & BDL & BDL & BDL & BDL & 100.00 \\
\hline 20 & BDL & BDL & BDL & BDL & -- \\
\hline Regression equation & Y= 3.360+(-0.085)X & \\
\hline $\mathrm{R}^{2}$ & 0.978 \\
\hline Half-life & 2.39 days \\
\hline Safe waiting period $: 15$ days
\end{tabular}

Jyothsnaet al. (2012) [7] reported that flubendiamide sprayed on gherkin @ 48 g a.i. ha-1gave initial deposit of $0.92 \mathrm{mg} \mathrm{kg}-1$ and residues reached Below Determination Level (BDL) by 10thday.The research findings of Paramasivam and Banerjee (2013)[8], showed that flubendiamide spray on cabbage @ $25 \mathrm{~g}$ a.i. ha-1 resulted in $0.31 \mathrm{mg} \mathrm{kg}-1$ deposits but persisted up to 15 days to reach BDL, indicating very slow dissipation rates on cabbage. Similar results were reported by Mohapatraet al. (2010) [9] where flubendiamide spray on cabbage @ $48 \mathrm{~g}$ a.i. ha-1 resulted in $0.49 \mathrm{mg} \mathrm{kg}-1$ deposit and took 15 days for dissipation to BDL.Based on the literature it is very clear that flubendiamide dissipates at very slow rate, but however, as the Codex MRL is $2 \mathrm{mg} \mathrm{kg}-1$ on capsicum, it can be safely recommended for use with 1 day PHI as initial deposits are below MRL in both cases. Since the Indian government recommends flubendiamide on capsicum, MRL of $2 \mathrm{mg} \mathrm{kg}-1$ can also be taken as provisional MRL as per FSSAI, since the initial deposits are very low due to low dose recommendation.

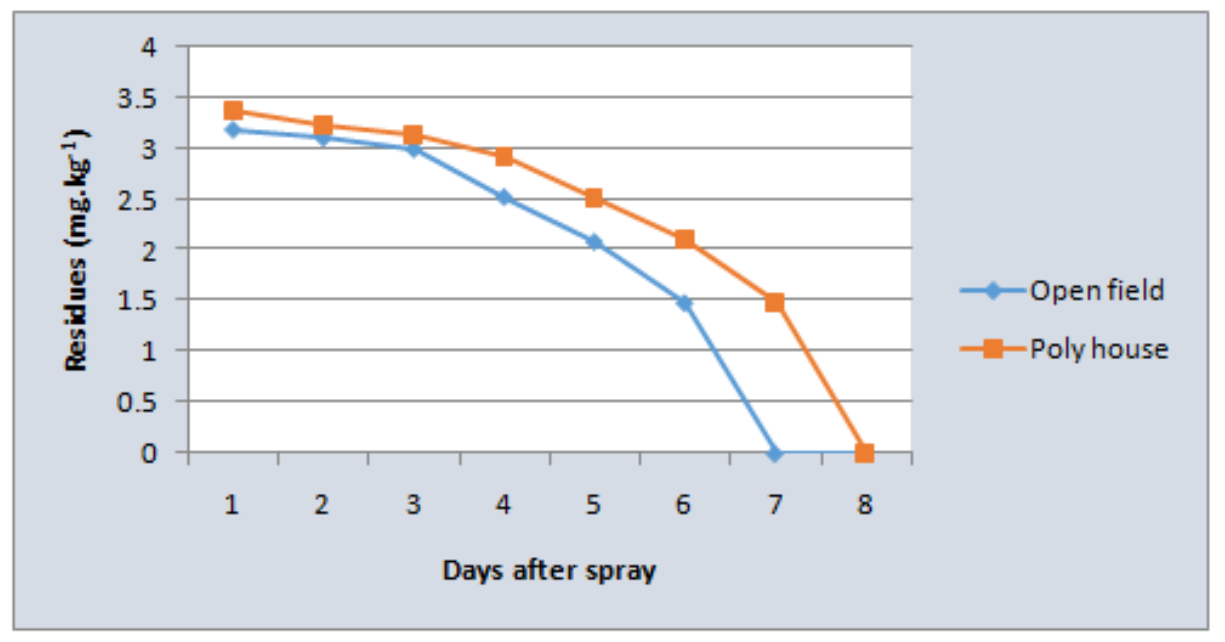

Figure1. Dissipation of flubendiamide in capsicum in open field and poly house conditions

The dissipation dynamics of flubendiamide when sprayed thrice @ $200 \mathrm{ml} \mathrm{ha}^{-1}$ were conducted in open field and poly house situation by collecting samples at $0,1,3,5,7,10,15$ and 20 days after the third spray and results are presented in Tables 4.26, 4.27 and Fig 4.15.

In open field situation, initial deposits of $1.50 \mathrm{mg} \mathrm{kg}^{-1}$ flubendiamide detected at 2 hours after last spray, dissipated to $1.27,0.97,0.33$ and $0.12 \mathrm{mg} \mathrm{kg}^{-1}$ by $1,3,5$ and 7 days after last spray, 
respectively. The residues reached BDL at $10^{\text {th }}$ day after spray. The dissipation pattern showed decrease of residues from first day to $10^{\text {th }}$ day and residues dissipated by $15.33,35.33,78.00,92.00$ and 98.00 per cent at $1,3,5,7$ and 10 days, respectively. The regression equation was $\mathrm{Y}=3.23+(-$ $0.126) \mathrm{X}$ with $\mathrm{R}^{2}$ of 0.894 . Based on first order of kinetics half - life period was worked out by using linear semi-logarithmic regression analysis and found to be 1.91 days. Safe waiting period for capsicum in open field conditions when flubendiamide @ $200 \mathrm{ml} \mathrm{ha}^{-1}$ sprayed thrice was 10 days.

In poly house conditions, initial deposits of $2.40 \mathrm{mg} \mathrm{kg}^{-1}$ flubendiamide detected at 2 hours after last spray, dissipated to $1.73,1.34,0.84,0.33,0.13$ at $1,3,5,7$ and 10 days after last spray, respectively. The residues reached BDL at $15^{\text {th }}$ day after spray. The dissipation pattern showed decrease of residues from first day to $15^{\text {th }}$ day and the residues dissipated by $27.91,61.27,65.0,86.25,94.58$ and 98.75 per cent at $1,3,5,7,10$ and 15 days, respectively. The regression equation was $\mathrm{Y}=3.360+(-$ $0.085) \mathrm{X}$ with $\mathrm{R}^{2}$ of 0.978 . The half - life and safe waiting periods were worked out for capsicum after three sprays of flubendiamide @ $200 \mathrm{ml} \mathrm{ha}^{-1}$ was 2.39 and 15 days, respectively.

Das et al. (2011)[10] found that the initial deposits of 0.28 and $0.53 \mathrm{mg} \mathrm{kg}^{-1}$ flubendiamide $39.35 \mathrm{SC}$ in/on okra fruits reached below determination level of $0.01 \mathrm{mg} \mathrm{g}^{-1}$ on the $7^{\text {th }}$ and $10^{\text {th }}$ day when applied at $24 \mathrm{~g}$ a.i.ha ${ }^{-1}$ and $48 \mathrm{~g}$ a.i.ha ${ }^{-1}$ doses, respectively and the half - life ranged from 4.7 to 5.1 days respectively. Similarly, Sahooet al. (2011)[11] also determined that three applications of flubendiamide 480SC @ 48 and $96 \mathrm{~g}$ a.i. $\mathrm{ha}^{-1}$ and sprays at 7 day intervals showed average initial deposits of 0.68 and $1.17 \mathrm{mg} \mathrm{kg}^{-1}$, respectively in chickpea pods and half-life of $1.39,1.44$ days and $0.77,0.86$ days in chickpea pods and leaves, respectively. Mohapatraet al. (2011) [12] reported the initial deposits of 0.83 and $1.68 \mu \mathrm{g} \cdot \mathrm{kg}^{-1}$ dissipated to BDL at 15 days in both the doses in cabbage.

Takkaret al. (2011) [13] also reported the residues of flubendiamide 480 SC on brinjal fruits at 90 and $180 \mathrm{~g}$ a.i.ha ${ }^{-1}$ and observed that the initial deposit of 0.33 and $0.61 \mathrm{mg} \mathrm{kg}^{-1}$, dissipated by 76.00 and 79.00 per cent after $3^{\text {rd }}$ day of application and half life ranged from 0.62 days and 0.54 days, at single and double doses, respectively.

Raghu et al. (2014) [14] found that in the open field study, initial deposits of $0.76 \mathrm{mg} \mathrm{kg}^{-1}$ of flubendiamide dissipated to $0.50,0.27$, and $0.15 \mathrm{mg} \mathrm{kg}^{-1}$ by 1,3 and 5 days after last spray, respectively, and below detectable level by $7^{\text {th }}$ day, whereas, in poly house initial deposit of $1.19 \mathrm{mg}$ $\mathrm{kg}^{-1}$ of flubendiamideat 2 hours after last spray, dissipated to $0.89,0.64,0.39,0.17$ and $0.14 \mathrm{mg} \mathrm{kg}^{-1}$ by $1,3,5,7$ and 10 days after last spray, respectively, and below detectable level by $15^{\text {th }}$ day. The variation in the initial deposits $\left(1.50\right.$ and $2.40 \mathrm{mg} \mathrm{kg}^{-1}$ in open and poly house conditions, respectively) half - life (1.91 and 2.39 days), waiting periods (10.00 and 150.00 days) of capsicum in the present study when compared to the results in other crops invested by earlier workers may be due to variation in dosages of application, change in matrix and climatic conditions.

The extraction method (QuEChERS) exhibited good linearity with respect to flubendiamide in solvent and was able to evaluate residues in capsicum. Initial deposits of $1.50 \mathrm{mg} \mathrm{kg}^{-1}$ were detected in capsicum samples collected from open filed, which dissipated to BDL in 10.0 days while in poly house, initial deposits of $2.40 \mathrm{mg} \mathrm{kg}^{-1}$ were dissipated to BDL in 15.0 days. The waiting period for safe harvest was worked out to be 10.0 and 20.0 days when spinosad 45 SC @ 75 ml a.i.ha ${ }^{-1}$ sprayed thrice in open and poly house conditions, respectively. Dissipation is slow in poly house compared to open fields due to various factors such as stability of temperature, light and heat transmission and relative humidity. During the experiment in open field conditions, variation in temperature, relative humidity and rainfall causes the dissipation of flubendiamideis fast.

\section{REFERENCES}

[1] Thacker, N. P., Bassin, J. K., Nitnaware, V., Vaidya, P., Das, S. K and Biswas, M. 2005. Proceeding of the national seminar on pesticide residues and their risk assessment. 65-77.

[2] Singh, B., Gupta, A., Bhatnagar, A and Parihar, N. S. 1999. Monitoring of pesticide residues in farmgate samples of capsicum. Pesticide Research Journal. 11(2): 207-209.

[3] Central Insecticide Board and Registration Committee. Major uses of pesticides. 20 June 2014. http://www.cibrc.nic.in

[4] Sahoo, S. K., Sharma, R. K., Battu, R. S and Singh. B. 2009. Dissipation kinetics of flubendiamide on chili and soil. Bulletin of Environmental Contamination and Toxicology. 83: 384-387. 


\section{VL Pathipati et al.}

[5] Sharma, B. N and Parihar, N. S. 2013. Dissipation and persistence of flubendiamide and thiacloprid in/on tomato and soil. Bulletin of Environmental Contamination and Toxicology. 90: 252-255.

[6] Kooner, R., Sahoo, S. K., Singh, B and Battu, R. S. 2010. Dissipation kinetics of fluubendiamide and thiacloprid on tomato (LycopersiconesculentumMill) and soil. Quality Assurance and Safety of Crops \& Foods. 36-40.

[7] Jyothsna, M., Reddy, D. J., Reddy, C. N and Rahman, S. M. A. S. 2012. Dissipation of flubendiamide, thiacloprid and flubendiamide+thiacloprid on gherkins. Indian Journal of Plant Protection. 40 (2): 133-140

[8] Paramasivam, M and Banerjee, H. 2013. Dissipation of flubendiamide residues in/on cabbage ( BrassicaoleraceaL). Environmental Monitoring and Assessment. 185: 1577-158.

[9] Mohapatra, S., Ahuja. A. K., Deepa, M., Sharma, D., Jagadish, G. K and Rashmi, N. 2010. Persistence and dissipation of flubendiamide and des-iodoflubendiamide in cabbage. (Brassica oleraceaLinne) and soil. Bulletin of Environmental Contamination and Toxicology. 85: 352-356.

[10] Das, S. K, Mukherjee, I and Das, S. K. 2011. Dissipation of flubendiamide in/on okra (Abelmoschusesculentus L.Moench) fruits. Bulletin of Environmental Contamination and Toxicology. 88: 381-384.

[11] Sahoo, S. K, Sharma, R. K, Battu, R. S and Singh. B. 2011. Dissipation kinetics of flubendiamide on chick pea. Bulletin of Environmental Contamination and Toxicology. 83: 214218.

[12] Mohapatra, S., Ahuja, A. K., Deepa, M., Jagadish, G. K., Rashmi, N. And Sharma, D. 2011. Development of analytical method for analysis of flubendiamide, des-iodo flubendiamide and study of their residues persistence in tomato and soil. Journal of Environmental Science and Health. 46 (3): 264-271.

[13] Takkar, R., Sahoo, S. K., Singh, G., Battu, R. S and Singh, B. 2011. Dissipation pattern of flubendiamide in/on brinjal (Solanummelongena L.). Environmental Monitoring and Assessment. 184: 5077-5083.

[14] Raghu, B., Vemuri, S.B., Rao, S.C and Reddy, P. N. 2014. Dissipation dynamics of certain insecticides in poly house and open field situation in chilli (Capsicum annum L.). Msc (Ag). Thesis submitted to Acharya N.G.Ranga Agricultural University, Hyderabad. 